\title{
Engineering Education: Challenges for Innovation
}

\author{
http://dx.doi.org/10.3991/ijep.v4i5.3539 \\ Teresa Restivo ${ }^{1}$ and Gustavo R. Alves ${ }^{2}$ \\ ${ }^{1}$ Faculty of Engineering, University of Porto, Porto, Portugal \\ 2 Polytechnic of Porto, School of Engineering, Porto, Portugal
}

\begin{abstract}
"Engineering Education: Challenges for Innovation" is the scope of the $1^{\text {st }}$ International Conference of the Portuguese Society for Engineering Education (in Portuguese: Sociedade Portuguesa para a Educação em Engenharia, SPEE) [1].

SPEE is a young society now completing four years since its public presentation and launching by the Faculty of Engineering of University of Porto, in February 19, 2010 .

During its first 12 months of activity, SPEE has launched its working groups named "Ethics in Engineering", "Continuing Education in Engineering" and "Information Technologies" and, later in 2011, the last one called "Tools to Develop Higher Order Thinking Skills". The Society was attaining by then its own internal momentum and so, developing the capabilities to go further with similar international associations.
\end{abstract}

So, in October 2011 SPEE, in cooperation with the International Society for Engineering Education (IGIP), SPEE had its first official participation in an International Conference, in the "SPEE-IGIP Flash Moment" within the $1^{\text {st }}$ World Engineering Education Flash Week. In 2012 the Society carried on with the organization of a Special Track "Talking about Teaching 2012" in the IGIP Annual Conference 2012 (Villach, Austria) and also has launched the call for an International Conference of the Society among its members. And this has been the smooth but firm way for reaching in 2013 its $1^{\text {st }}$ International Conference CISPEE2013, in Porto, Portugal, complemented by the second TaT Special Track within IGIP Annual Conference 2013, TaT'13, in Kazan, Russia.

During TaT'12 and TaT'13, Special Issues of the International Journal for Engineering Pedagogy have been published and now, the present Special Issue, will be again propagating works accomplishing one of the missions of the SPEE - to promote Engineering Education by sharing experiences, projects, results and discussions in order to contribute for research and for teachers' scientific and professional development. This has also been the purpose of its Newsletters, which brought, when it was launched and every three months, the cooperation of national and international societies and organizations as well as the Society members and international colleagues [2]. In this way, SPEE "will carry on performing its important task within the engineering education community, blessed with the devoted commitment of its members and the invaluable cooperation of international colleagues and sister societies" [3].
The Polytechnic of Porto - School of Engineering (IPP/ISEP) hosted CISPEE2013 on October $31^{\text {st }}$ and November $1^{\text {st }}, 2013$, in Porto, Portugal.

CISPEE2013 received 80 submissions (with authors from 21 different nationalities), from which 48 were accepted as full papers (60\% acceptance rate), 18 were proposed for presentation as posters, 10 were rejected and 4 were considered not valid. All submissions were double blind reviewed by at least 3 independent reviewers, with conflicting cases raising additional reviews. This procedure allowed ensuring a high-quality technical program with 8 oral presentation sessions devoted to (1) Designing Courses for Higher Order Thinking, (2) Role of Engineers and Engineering Education in Society, (3) Computers and Mobile Devices in Egineering Education, (4) Problem Solving and Creativity, (5) Using Online Tools to Facilitate Learning, (6) Mathematical Competences and Computacional Tools for Teaching Mathematics in Engineering, (7) Research Aspects in Engineering Education, and (8) Engineering Education Case Studies.

The present Special Issue contains a selection of highly rated papers, from CISPEE2013, whose authors were asked to incorporate at least $30 \%$ of new / revised material, in relation to the version presented at the conference and included in its proceedings, indexed by IEEE Xplore [4]. We sincerely hope you appreciate reading this selection.

\section{REFERENCES}

[1] http://www.isep.ipp.pt/cispee

[2] http://spee.org.pt/index.php/newsletter/

[3] Director Board Message, SPEE Newsletter $n^{\circ}$ 5, pp. 3-4, ISSN 2182-0945, http://spee.org.pt/index.php/newsletter/55-newslettern-5-fevereiro-2012

[4] Proceedings of the $20131^{\text {st }}$ International Conference of the Portuguese Society for Engineering Education, available at http://ieeexplore.ieee.org/xpl/mostRecentIssue.jsp?punumber=669 3053 , accessed January $14^{\text {th }}, 2014$.

\section{AUTHORS}

Teresa Restivo is with IDMEC, Faculty of Engineering, University of Porto, Portugal (e-mail: trestivo@fe.up.pt).

Gustavo R. Alves is with the Electrical Engineering Department, School of Engineering, Polytechnic of Porto, Portugal (e-mail: gca@isep.ipp.pt). 